\title{
Sensitivity Analysis based Optimal Location and Tuning of Static VAR Compensator using Firefly Algorithm
}

\author{
B. Venkateswara Rao* and G. V. Nagesh Kumar
}

GITAM University, Visakhapatnam, Andhra Pradesh, India; gundavarapu_kumar@yahoo.com

\begin{abstract}
This paper presents a new Meta heuristic optimization algorithm called firefly algorithm (FA) used to solve the multi objective optimal power flow to identify the optimal setting of Static VAR Compensator (SVC) and optimal location is identified by using sensitivity analysis when the system is operating under normal and overloaded conditions. Sensitivity analysis based Voltage collapse proximity Index is proposed for placing the SVC at appropriate location under normal and over loaded conditions. Once the location to install SVC is identified, the optimal allocation of SVC is determined through firefly algorithm based A multi-criterion objective function comprising of four objectives minimize total power loss, minimize total voltage magnitude deviations, minimize the fuel cost of total generation and minimize the branch loading to obtain the optimal power flow. Simulations have been implemented in MATLAB and the IEEE 14-bus, IEEE 30-bus and IEEE 57-bus systems have been used as a case study. The results we have obtained indicate that installing SVC can significantly enhance the voltage stability of power system. Also for the purpose of comparison the proposed technique was compared with another optimization technique namely Genetic Algorithm (GA). The results we have obtained indicate that FA is an easy to use, robust, and powerful optimization technique compared with GA.
\end{abstract}

Keywords: Firefly Algorithm, Optimization, Static VAR Compensator, VCPI

Nomenclature

$V_{i} \theta \quad$ : Complex voltage at bus $\mathrm{i}$;

$\theta_{i j} \quad$ : Difference between $\theta_{i}$ and $\theta_{j}$

$B_{s v c} \quad$ : Susceptance of SVC

$\mathrm{F}$ : Objective function

FC : Total fuel cost of all the generators

$F_{\text {ploss }}:$ Total complex power losses

$F_{v d} \quad$ : Net voltage deviation

$F_{s} \quad$ : Total loading capacity of transmission lines

$T L$ : Active Power transmission line losses

$Q_{s v c}:$ The svc reactive power in MVAR

$V_{i} \quad$ : Bus voltage at $\mathrm{i}^{\text {th }}$ bus

$V_{i}^{\text {min }}:$ Minimum voltage at bus i

$V_{i}^{\max }:$ Maximum voltage at bus i

$P_{G}^{\min }:$ Minimum real power generation

$P_{G}^{\max }:$ Maximum real power generation

$Q_{G}^{\min }:$ Minimum reactive power generation
$Q_{G}^{\max }:$ Maximum reactive power generation

$S_{i j} \quad$ : Apparent power flow from bus $\mathrm{i}$ to $\mathrm{j}$

$P_{i j} \quad$ : Active power flow from bus i to $j$

$Q_{i j} \quad:$ Reactive power flow from bus $\mathrm{i}$ to $\mathrm{j}$

$Y_{i j} \quad$ : Admittance of the element between bus $i$ and $j$

\section{Introduction}

Modern electric power utilities are facing many problems due to increasing complexity in their operation and structure. Voltage instability and voltage collapse have been considered as a major threat to present power system networks due to their stressed operation ${ }^{1}$. It is very important to do the power system analysis with respect to voltage stability ${ }^{2}$. In recent years, the transmission lines are operated under the heavily stressed condition, hence there is a risk of consequent voltage instability in 
the power network. Owing to lack of new generation, transmission facilities and over exploitation of the existing facilities leads to power system instability. Conventional power systems are controlled mechanically. However, control through mechanical devices is not as reliable as they tend to wear out quickly compared to the static devices. This necessitates power flow control to shift from mechanical devices to static devices. There is a multifunctional control device which can be effectively control the load flow distribution and the power transfer capability is the Flexible Alternating Current Transmission System (FACTS) device ${ }^{3}$. The FACTS device performance depends upon its location and parameter setting. The power electronic based FACTS have been introduced in 1980's, provided a highly efficient and economical means to control the power transfer in interconnected AC transmission systems ${ }^{4}$. It is essential to utilize better the existing power networks to increase capacities by installing FACTS controllers. Power flow through an AC line is a function of phase angles, bus voltages and line impedance. Using FACTS devices, these variables can be effectively and efficiently controlled. A FACTS device in a power system improves the voltage stability, reduces the power loss and also improves the load ability of the system. However, controlling power flow is the main function of FACTS ${ }^{5,6}$.

The SVC is most commonly used shunt connected FACTS device capable of providing simultaneous control of voltage magnitude and reactive power flows. Owing to its fast response and unrivalled functionality, it is able to solve problems related to power flow control ${ }^{7,8}$. The SVC, constructed by the combination of the fixed capacitor and thyristor controlled reactor ${ }^{9,10}$. It is popularly known as FC-TCR that can inject the capacitive reactive power to the system to control power flow in transmission lines and controlling its parameters, like the voltage magnitude and the phase angle ${ }^{11,12}$.

This paper presents a new Meta heuristic optimization technique called Firefly Algorithm (FA) ${ }^{13}$ is introduced to find the optimal size of SVC device to avoid voltage instability and Sensitivity analysis based Voltage Collapse Proximity Index (VCPI) is used to identify the optimal location of SVC. Its performance is compared with Genetic_Algorithm (GA) ${ }^{14,15}$ technique. The real and reactive power generation values and voltage limits for the buses are taken as constraints during the optimization ${ }^{16,17}$. The obtained results show that SVC is the most effective shunt compensation devices that can significantly increase the voltage stability of the power system. Computer simulations using MATLAB were done for the IEEE14 bus system and IEEE 30 bus system ${ }^{18,19}$.

\section{Static VAR Compensator}

Static VAR Compensator (SVC) is a shunt connected FACTS controller whose main functionality is to regulate the voltage at a given bus by controlling its equivalent reactance ${ }^{20,21}$. SVC normally includes a combination of mechanically controlled and thyristor controlled shunt capacitors and reactors. The most popular configuration for continuously controlled SVC is the combination of fixed capacitor and thyristor controlled reactor. The SVC is taken to be a continuous, variable susceptance, which is adjusted in order to achieve a specified voltage magnitude while satisfying constraint conditions ${ }^{22}$. SVC total susceptance model represents a changing susceptance. Bsvc represents the fundamental frequency equivalent susceptance of all shunt modules making up the SVC. The SVC is treated as a generator behind an inductive reactance when the SVC is operating within the limits. The reactance represents the SVC voltage regulation characteristic, i.e., SVC's slope. The slope can be represented by connecting the SVC models to an auxiliary bus coupled to the high voltage bus by an inductive reactance consisting of the transformer reactance and the SVC slope, in per unit (p.u) on the SVC base ${ }^{23}$. A simpler representation assumes that the SVC slope for voltage regulation is zero. This assumption may be acceptable as long as the SVC is operating within their limits, but may be lead to errors if the SVC is operating close to its reactive limits.

The SVC may have two characters: inductive or capacitive, respectively to absorb or provide reactive power. The SVC is represented by a shunt variable susceptance inserted at the bus. It may take values characterized by the reactive power $\mathrm{Q}_{\text {svc }}$ injected or absorbed at the voltage of 1 p.u. The possible values are function of the considered power system ${ }^{24}$.

The variable susceptance model and its equivalent circuit is shown in Figure 1. SVC can be represented as an adjustable reactance.

In general, the transfer admittance equation for the variable shunt compensator is

$$
I=j B V_{k}
$$

and the reactive power equation is, 


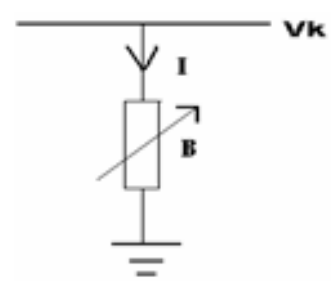

Figure 1 Variable shunt susceptance.

$$
Q_{k}=-V_{k}^{2} B
$$

The modified equation of the SVC is given by the following equation where the total susceptance Bsvc is taken to be the state variable.

$$
\left[\begin{array}{l}
\Delta P_{k} \\
\Delta Q_{k}
\end{array}\right]^{i}=\left[\begin{array}{ll}
0 & 0 \\
0 & Q_{k}
\end{array}\right]^{i}\left[\begin{array}{l}
\Delta \theta_{k} \\
\Delta B_{s v c} / B_{s v c}
\end{array}\right]^{i}
$$

at the end of iteration $i$, the variable shunt susceptance Bsvc updated according to the equation given below;

$$
B_{s v c}^{i+1}=B_{s v c}^{i}+\left(\frac{\Delta B_{s v c}}{B_{s v c}}\right)^{i+1} B_{s v c}^{i}
$$

Based on the equivalent circuit of SVC (susceptance model) in Figure 1, the power flow equations are given below.

The current drawn by the SVC is

$$
I_{s v c}=j B_{s v c} V_{k}
$$

Reactive power drawn by the SVC, which is also reactive power injected at bus $k$, is

$$
Q_{s v c}=-V_{k}^{2} B_{S V C}
$$

The SVC linearized power equations are combined with linearized system of equations corresponding to the rest of the network

$$
[F(x x)]=[J][\Delta X]
$$

where,

$$
[F(x x)]=\left[\Delta P_{k} \Delta P_{m} \Delta Q_{k} \Delta Q_{m}\right]^{T}
$$

$\Delta \mathrm{P}_{\mathrm{k}}, \Delta \mathrm{Q}_{\mathrm{k}}$ are the power mismatch equations, and superscript ' $\mathrm{T}$ ' indicates transposition.

$[\Delta \mathrm{X}]$ is the solution vector

$[\mathrm{J}]$ is the Jacobian matrix
For the case when SVC Susceptance necessary to maintain the nodal voltage magnitude at the specified value.

$$
[\Delta X]=\left[\begin{array}{lll}
\Delta \theta_{k} & \Delta \theta_{m} & \Delta V_{k}
\end{array} V_{m}\right]^{T}
$$

In this case, $\mathrm{Vk}$ is maintained constant at $1 \mathrm{pu}$. The modified Jacobian matrix is given as

$$
[J]=\left[\begin{array}{llll}
\frac{\partial P_{k}}{\partial \theta_{k}} & \frac{\partial P_{k}}{\partial \theta_{m}} & \frac{\partial P_{k}}{\partial V_{k}} & \frac{\partial P_{k}}{\partial V_{m}} \\
\frac{\partial P_{m}}{\partial \theta_{k}} & \frac{\partial P_{m}}{\partial \theta_{m}} & \frac{\partial P_{m}}{\partial V_{k}} & \frac{\partial P_{m}}{\partial V_{m}} \\
\frac{\partial Q_{k}}{\partial \theta_{k}} & \frac{\partial Q_{k}}{\partial \theta_{m}} & \frac{\partial Q_{k}}{\partial V_{k}} & \frac{\partial Q_{k}}{\partial V_{m}} \\
\frac{\partial Q_{m}}{\partial \theta_{k}} & \frac{\partial Q_{m}}{\partial \theta_{m}} & \frac{\partial Q_{m}}{\partial V_{k}} & \frac{\partial Q_{m}}{\partial V_{m}}
\end{array}\right]
$$

The starting values of the SVC susceptance is taken to be $\mathrm{B}=0.02$ p.u, $\mathrm{B}_{\min }=-1.5 \mathrm{p} . \mathrm{u} \mathrm{B}_{\max }=1.5 \mathrm{p} . \mathrm{u}$

\section{Problem Formulation}

In the present study, the multi objective function is formulated to find optimal allocation of SVC device by minimizing certain objective functions subject to satisfying some network constraints. The multi-objective problem can be written mathematically as follows as in Malakar et $\mathrm{al}^{29}$.

\subsection{Objective function}

For a given system load, we look for the best configuration of SVC device minimizing the following objective function:

$\operatorname{Min} \mathrm{F}=\operatorname{Min}\left(\mathrm{w} 1^{*} \mathrm{FC}+\mathrm{w} 2^{*}\right.$ FpLoss $\left.+\mathrm{w} 3^{*} \mathrm{FvD}+\mathrm{w} 4^{*} \mathrm{Fs}\right)$

where w1, w2, w3, w4 are the weighting factors.

$$
\mathrm{w} 1+\mathrm{w} 2+\mathrm{w} 3+\mathrm{w} 4=1
$$

\subsubsection{Fuel Cost}

The objective function considering the minimization of total generation cost can be represented by following quadratic equation

$$
\begin{aligned}
& \mathrm{FC}=\min \left(\sum_{i=1}^{n g}\left[a_{i}+b_{i} P_{G i}+c_{i} P_{\mathrm{Gi}}^{2}\right]\right) \\
& \text { where } \mathrm{ng}=\text { no. of generator buses }
\end{aligned}
$$

a, b, c are the fuel cost coefficients of a generator unit 


\subsubsection{Complex Power Loss}

This objective consists of minimizing the both real power losses and reactive power losses in the transmission lines. It can be expressed as

$$
\text { FPLoss }=\min \left(P_{\text {Loss }}\right)=\min \left(\sum_{k=1}^{n t l}\left[S_{\mathrm{ij}}^{\mathrm{k}}+S_{\mathrm{ji}}^{\mathrm{k}}\right]\right)
$$

where ntl $=$ no.of transmission lines

$\mathrm{S}_{\mathrm{ij}}$ is the total complex power flow of line $\mathrm{i}-\mathrm{j}$

\subsubsection{Voltage Deviation}

To have a good voltage performance, the voltage deviation at each bus must be made as small as possible. The Voltage Deviation (VD) can be expressed as:

$$
F_{V D}=\min (V D)=\min \left(\sum_{k=1}^{N b u s}\left|V_{k}-V_{\mathrm{k}}^{\text {ref }}\right|^{2}\right)
$$

$\mathrm{V}_{\mathrm{k}}$ is the voltage magnitude at bus $\mathrm{k}$

\subsubsection{Branch Loading}

This objective consists of minimizing the branch loading in the transmission lines and the aim of the optimization is to enhance the security level of the system.

It can be expressed as

$$
F_{S}=\min (S)=\min \left(\sum_{k=1}^{n t l} w_{k}\left(S_{k} / S_{\max k}\right)^{2}\right)
$$

$S_{k}$ is the apparent power in line $k$ and $S_{\text {maxk }}$ is the maximum apparent power in line $k$.

\subsubsection{Equality Constraints}

$$
\begin{aligned}
& P_{G i}=\left(P_{D_{i}}\right)+\left(P_{L}\right) \text { where } \mathrm{i}=1,2,3, \ldots, \mathrm{N} \text { bus } \\
& Q_{G i}=\left(\mathrm{Q}_{D_{i}}\right)+\left(\mathrm{Q}_{L}\right) \text { where } \mathrm{i}=1,2,3, \ldots, \mathrm{N} \text { bus } \\
& \mathrm{P}_{\mathrm{L}} \text { is total active power losses } \\
& \mathrm{Q}_{\mathrm{L}} \text { is total reactive power losses } \\
& \mathrm{N}_{\text {bus }} \text { is total number of buses }
\end{aligned}
$$

\subsubsection{Inequality Constraints}

Voltage limits:

$$
V_{i}^{\min } \leq V_{i} \leq V_{i}^{\max } \text { where } i=1,2,3, \ldots, \mathrm{N} \text { bus }
$$

Real power generation limit:

$$
\begin{aligned}
& P_{g i}^{\min } \leq P_{g i} \leq P_{g i}^{\max } \text { where } i=1,2,3, \ldots, n g \\
& \text { and } \mathrm{ng}=\text { no. of generator buses }
\end{aligned}
$$

Reactive Power limits:

$$
\begin{aligned}
& Q_{g i}^{\min } \leq Q_{g i} \leq Q_{g i}^{\max } \text { where } i=1,2,3, \ldots, n g \\
& \text { and } \mathrm{ng}=\text { no. of generator buses }
\end{aligned}
$$

SVC Limits

$$
B_{s v c}^{\min } \leq B_{s v c} \leq B_{s v c}^{\max }
$$

\section{Optimal Placement of SVC}

The optimal locations to install the FACTS devices for Optimal Power Flow under normal and overload condition are presented in this section. The OPF solution is obtained by solving the optimization problem using Firefly Algorithm programming method. The solution obtained at this point is optimal but some of the bus voltages are less. This voltage instability is however eliminated by placing SVC in the appropriate location ${ }^{30,31}$.

The important issue of the VAR planning problem is to determine the locations for installing new VAR sources. An appropriate selection of candidate buses can both reduce the solution space and obtain a better final optimal solution. In the past the determination of the weak buses was based on the experience of the planner, environmental limit and economic considerations. In this paper, Heavy load bus-oriented criterion is developed in order to determine the weak buses. This criterion is based on the intuitive concept that a heavy load bus is usually a very voltage-sensitive bus and installing new VAR sources may be necessary. These heavy load buses are then primary choices as candidate buses. In the following, computationally efficient and simple indices presented earlier are used to identify weak buses in electrical power systems. The indices is summarized as follows, A sensitivity analysis computation such as the total change in generator reactive power for a change in reactive demand is one method. It is called voltage collapse proximity indicator $(\mathrm{VCPI})^{32}$. It goes from unity at no load to infinity at maximum load. Near maximum load, extremely large amount of reactive power are required at the sending end to support an incremental increase in load. The VCPI is thus a very sensitive indicator of impending voltage collapse.

The voltage collapse proximity indicator for each load bus, considering reactive power only, is:

$$
V C P I_{Q i}=\left(\sum \Delta Q_{g}\right) / \Delta Q_{i}
$$


where $\Delta Q_{g}$ is the change in reactive power output at generators for a change in reactive load at bus $i$.

The buses with the largest values of $\mathrm{VCPI}_{\mathrm{Qi}}$ are the most effective locations for SVC placement. In this study $20 \%$ of the reactive load increased in respective load buses and compute the $\mathrm{VCPI}_{\mathrm{Qi}}$. Table 1 indicates the $\mathrm{VCPI}_{\mathrm{Qi}} \mathrm{cal}$ culated bus and it's index for IEEE 14 bus system. From this table it is also observed that bus no 9 was the weakest bus compared to all other load buses. So bus no 9 is most suitable location for placement of SVC. Similarly Table 2 indicates that bus no 22 have rank 1 that means in IEEE 30 bus system bus no 22 is the most suitable location for placement of SVC followed by the buses 26, 24, 21 etc.

\section{Firefly Algorithm}

Firefly Algorithm (FA) was developed by Dr Xin-She Yang at Cambridge University in 2007. FA is based on natural phenomenal behaviour of the firefly which is developed for solving the multimodal optimization problem ${ }^{25,26}$. Fireflies are also called as lighting bugs these are one of the most special and fascinating creatures in nature. There are about thousands of fireflies where the flashes often unique on a particular firefly. For simplicity, the following three ideal rules are introduced in FA development those are 1) All the fireflies are gender-free that is every firefly will attract the other firefly substantive of their sex, 2) Attractiveness depend on their brightness. The less bright one will move towards the brighter one, 3) the landscape of the objective function affects the firefly brightness. Let us consider the continuous constrained optimization problem where the task is to minimize cost function $\mathrm{f}(\mathrm{x})$. Firefly algorithm

Table 1. Weak buses ordering in IEEE 14 bus system

\begin{tabular}{lcl}
\hline Rank & VCPI $_{\text {Qi }}$ Bus & Index VCPI $_{\text {Qi }}$ \\
\hline 1 & 9 & 1.120482 \\
2 & 14 & 1.114 \\
3 & 10 & 1.103448 \\
4 & 13 & 1.060345 \\
5 & 11 & 1.055556 \\
6 & 12 & 1.03125 \\
\hline
\end{tabular}

is a speedily converging algorithm. The solution for the algorithm depends on the selection of swarm size, maximum attractiveness value, the absorption coefficient value and the iteration limit. The basic steps of the FA can be summarized as the pseudo code $\mathrm{c}^{27,28}$.

Firefly Algorithm

$$
\begin{aligned}
& \text { Objective function } f(\mathbf{x}), \mathbf{x}=(x 1, \ldots, x d) T \\
& \text { Generate initial population of fireflies } \mathbf{x}_{i i}(i=1,2, \ldots, n) \\
& \text { Light intensity } I_{i i} \text { at } x_{i i} \text { is determined by } f\left(\mathbf{x}_{i i}\right) \\
& \text { Define light absorption coefficient } \gamma \\
& \text { while }(t<\text { MaxGeneration) } \\
& \text { for } i i=1: n \text { all } n \text { fireflies } \\
& \text { for } j j=1: \text { ii all } n \text { fireflies } \\
& \text { if }\left(I_{j j}>I_{i i}\right) \text {, More firefly ii towards } j j \text { in d-dimension; } \\
& \text { end if }
\end{aligned}
$$$$
\text { Attractiveness varies with distance } r
$$$$
\text { Evaluate new solutions and modify the light intensity }
$$$$
\text { end for } j j
$$$$
\text { end for } i i
$$$$
\text { Rank all the fireflies and find the current best firefly }
$$$$
\text { end while }
$$$$
\text { Post process results and visualization }
$$

Pseudo code of the FA.

\section{Result and Discussion}

In order to demonstrate the performance of the Firefly Algorithm in Optimal Power Flow with SVC, IEEE14 bus system and IEEE30 bus system are considered. An OPF program using Firefly algorithm approach has been written using MATLAB without the SVC, which was further extended with the SVC. A MATLAB program

\begin{tabular}{|c|c|c|c|c|c|c|c|c|c|c|}
\hline Rank & 1 & 2 & 3 & 4 & 5 & 6 & 7 & 8 & 9 & 10 \\
\hline VCPIQi Bus & 22 & 26 & 24 & 21 & 23 & 30 & 20 & 19 & 10 & 12 \\
\hline Index VCPIQi & 1.2175 & 1.21739 & 1.20895 & 1.20535 & 1.1875 & 1.18421 & 1.18 & 1.17647 & 1.175 & 1.17 \\
\hline
\end{tabular}
is coded for the test system and the results have been tabulated. The input parameters of Firefly Algorithm for the test system are given in the Table 3.

\subsection{Bus System}

In IEEE 14 bus system bus no 1 is considered as a slack bus and bus numbers 2, 3, 6, 8 are considered as a PV buses all other buses are considered as load buses. This

Table 2. Weak buses ordering in IEEE 30 bus system 
system has 20 interconnected lines. A MATLAB program is coded for the test system and the results have been tabulated. Table 4 indicates the generators coefficients, minimum and maximum limit of real power generation for generator buses.

Table 5 indicates that by using FA in Optimal Power Flow with SVC reduces the active power losses. Table 5 also indicates the size of SVC in MVAR at different buses. By placing the SVC at Bus no 9 reduced the losses as compared to all other locations and SVC value was tuned to 24.96MVAR using FA.

Table 6 indicates the voltage magnitudes in FA-OPF without SVC and FA-OPF with SVC (By placing SVC at Bus No 9). There was a good improvement in voltage profile with SVC in FA based OPF. Figure 2 represents the active power losses for placement of SVC at different

Table 3. Input parameters of Firefly Algorithm

\begin{tabular}{llc}
\hline S.No & Parameters & Quantity \\
\hline 1 & $\begin{array}{l}\text { Number of } \\
\text { fireflies }\end{array}$ & 50 \\
2 & Max & 500 \\
3 & Generation & 0.25 \\
4 & Alpha & 0.2 \\
5 & Beta & 1 \\
\hline
\end{tabular}

Table 4. Generator characteristics of IEEE 14 bus system

\begin{tabular}{lccccr}
\hline $\begin{array}{l}\text { Generator } \\
\text { BUS NO }\end{array}$ & a & b & c & $\boldsymbol{P}_{\boldsymbol{G}}^{\text {min }}$ & $\boldsymbol{P}_{\boldsymbol{G}}^{\text {max }}$ \\
\hline 1 & 0.005 & 2.45 & 105 & 10 & 200 \\
2 & 0.005 & 3.51 & 44.1 & 20 & 80 \\
3 & 0.005 & 3.89 & 40.6 & 20 & 50 \\
6 & 0.005 & 3.25 & 0 & 10 & 35 \\
8 & 0.005 & 3 & 0 & 10 & 30 \\
\hline
\end{tabular}

Table 5. Incorporation OF SVC Model in FA-OPF and GA-OPF Algorithms in 5 different Locations

\begin{tabular}{|c|c|c|c|c|c|}
\hline S.No & $\begin{array}{c}\text { SVC } \\
\text { placed } \\
\text { Bus No }\end{array}$ & $\begin{array}{l}\text { FA-OPF } \\
\text { SVC } \\
\text { Size in } \\
\text { MVAR }\end{array}$ & $\begin{array}{l}\text { GA-OPF } \\
\text { SVC Size } \\
\text { in MVAR }\end{array}$ & $\begin{array}{l}\text { FA-OPF } \\
\text { Active } \\
\text { Power } \\
\text { Losses } \\
\text { in MW }\end{array}$ & $\begin{array}{c}\text { GA-OPF } \\
\text { Active } \\
\text { Power } \\
\text { Losses in } \\
\text { MW }\end{array}$ \\
\hline 1 & 6 & 0.0200 & 0.0200 & 3.7301 & 5.6467 \\
\hline 2 & 7 & 0.1242 & 0.1249 & 3.6660 & 5.5783 \\
\hline 3 & 9 & 0.2496 & 0.2512 & 3.6255 & 5.5380 \\
\hline 4 & 10 & 0.2125 & 0.2137 & 3.6749 & 5.5897 \\
\hline 5 & 11 & 0.1443 & 0.1451 & 3.7317 & 5.6482 \\
\hline
\end{tabular}

Table 6. Comparison of bus voltages for 30 bus system using FA-OPF without and with SVC

\begin{tabular}{llll}
\hline $\begin{array}{l}\text { BUS } \\
\text { No }\end{array}$ & NR method & $\begin{array}{c}\text { FA-OPF } \\
\text { without SVC }\end{array}$ & $\begin{array}{c}\text { FA-OPF with SVC } \\
\text { at Bus No 9 }\end{array}$ \\
\hline & $\begin{array}{l}\text { Voltage } \\
\text { Magnitude }\end{array}$ & $\begin{array}{l}\text { Voltage } \\
\text { Magnitude }\end{array}$ & $\begin{array}{l}\text { Voltage } \\
\text { Magnitude }\end{array}$ \\
1 & 1.06 & 1.06 & 1.06 \\
2 & 1.045 & 1.045 & 1.045 \\
3 & 1.01 & 0.9983 & 1.01 \\
4 & 1.0127 & 1.0103 & 1.0183 \\
5 & 1.0201 & 1.0188 & 1.0241 \\
6 & 1 & 1 & 1 \\
7 & 0.9825 & 0.9882 & 1.0038 \\
8 & 1 & 1 & 1 \\
9 & 0.9582 & 0.9705 & 1 \\
10 & 0.9574 & 0.9674 & 0.992 \\
11 & 0.9746 & 0.9795 & 0.9921 \\
12 & 0.9774 & 0.983 & 0.9853 \\
13 & 0.9661 & 0.9764 & 0.9808 \\
14 & 0.9078 & 0.9535 & 0.9724 \\
\hline
\end{tabular}

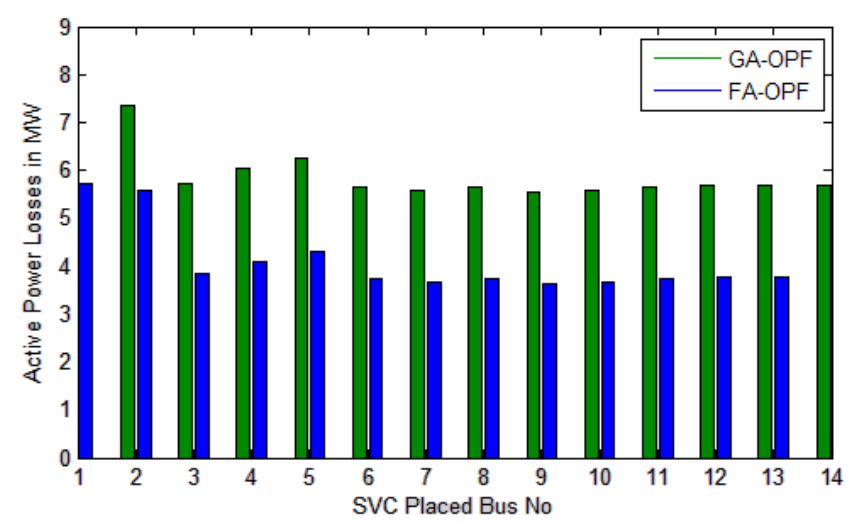

Figure 2 Comparison of Active power losses in a 14 bus system.

buses using GA and FA based OPF. By placing the SVC at bus 9 the active power losses are less as compared to other buses. The Active power losses are $3.6255 \mathrm{MW}$ when the SVC is placed in bus no 9. The active power generation, cost and power loss for IEEE 14 bus test system without and with SVC is shown in Table 7. Active power losses are reduced to $3.6255 \mathrm{MW}$ from $7.8348 \mathrm{MW}$ by placing SVC. The SVC is set to regulate bus no 9 nodal voltage magnitude at 1 p.u. and SVC value was tuned to 24.96MVAR using FA. Table 8 represents the voltage deviation, SVC susceptance value and active power losses for IEEE 14 bus system without SVC and with SVC using GA-OPF and FA-OPF for different loading conditions. 
Table 7. Comparison of Real power loss for 30 bus test system without and with SVC (SVC placed at bus number 9)

\begin{tabular}{llcc}
\hline S.No & Method & $\begin{array}{c}\text { Real power } \\
\text { generation } \\
(\mathrm{MW})\end{array}$ & $\begin{array}{c}\text { Total real } \\
\text { power loss } \\
(\mathrm{MW})\end{array}$ \\
\hline 1 & $\begin{array}{l}\text { NR method } \\
\text { NR with SVC } \\
(\mathrm{B}=0.2385)\end{array}$ & 267.1348 & 7.8348 \\
3 & $\begin{array}{l}\text { GA-OPF } \\
\text { without SVC }\end{array}$ & 266.0955 & 6.7955 \\
4 & $\begin{array}{l}\text { GA-OPF with } \\
\text { SVC }\end{array}$ & 264.1599 & 5.8599 \\
5 & $\begin{array}{l}\text { FA-OPF } \\
\text { without SVC }\end{array}$ & 263.2460 & 5.5380 \\
6 & $\begin{array}{l}\text { FA-OPF with } \\
\text { SVC }\end{array}$ & 262.9255 & 3.9460 \\
\hline
\end{tabular}

Table 8. Real Power loss, Voltage deviation and rating of SVC for different load scenario for IEEE 14 bus system using GA and FA (SVC placed at bus no 9)

\begin{tabular}{|c|c|c|c|c|c|}
\hline \multirow{2}{*}{$\begin{array}{l}\text { Loading } \\
\text { condition }\end{array}$} & & \multicolumn{3}{|c|}{ GA-OPF } & \multirow{2}{*}{$\begin{array}{c}\text { FA-OPF } \\
\text { with } \\
\text { SVC }\end{array}$} \\
\hline & & GA-OPF & $\begin{array}{l}\text { with } \\
\text { SVC }\end{array}$ & FA-OPF & \\
\hline \multirow{3}{*}{$\begin{array}{l}\text { Normal } \\
\text { loading }\end{array}$} & $\begin{array}{l}\text { SVC } \\
\text { Rating }\end{array}$ & - & 0.2512 & - & 0.2496 \\
\hline & $\begin{array}{l}\text { Voltage } \\
\text { Deviation }\end{array}$ & 0.3251 & 0.2388 & 0.3173 & 0.2385 \\
\hline & $\begin{array}{l}\text { Real } \\
\text { Power } \\
\text { losses }\end{array}$ & 5.8599 & 5.5380 & 3.9460 & 3.6255 \\
\hline \multirow{3}{*}{$\begin{array}{l}110 \% \\
\text { loading }\end{array}$} & $\begin{array}{l}\text { SVC } \\
\text { Rating }\end{array}$ & - & 0.273 & - & 0.2681 \\
\hline & $\begin{array}{l}\text { Voltage } \\
\text { Deviation }\end{array}$ & 0.3313 & 0.2491 & 0.3248 & 0.2465 \\
\hline & $\begin{array}{l}\text { Real } \\
\text { Power } \\
\text { losses }\end{array}$ & 6.8823 & 6.2906 & 6.0635 & 5.2755 \\
\hline \multirow{3}{*}{$\begin{array}{l}120 \% \\
\text { loading }\end{array}$} & $\begin{array}{l}\text { SVC } \\
\text { Rating }\end{array}$ & - & 0.2883 & - & 0.2831 \\
\hline & $\begin{array}{l}\text { Voltage } \\
\text { Deviation }\end{array}$ & 0.3451 & 0.3242 & 0.3228 & 0.2868 \\
\hline & $\begin{array}{l}\text { Real } \\
\text { Power } \\
\text { losses }\end{array}$ & 11.8191 & 11.6195 & 8.9255 & 8.254 \\
\hline \multirow{3}{*}{$\begin{array}{l}150 \% \\
\text { loading }\end{array}$} & $\begin{array}{l}\text { SVC } \\
\text { Rating }\end{array}$ & - & 0.3460 & - & 0.3452 \\
\hline & $\begin{array}{l}\text { Voltage } \\
\text { Deviation }\end{array}$ & & 0.3827 & 0.4625 & 0.3227 \\
\hline & $\begin{array}{l}\text { Real } \\
\text { Power } \\
\text { losses }\end{array}$ & 22.1482 & 21.8334 & 20.1800 & 16.4516 \\
\hline
\end{tabular}

\subsection{Bus System}

In IEEE 30 bus system bus no 1 is considered as a slack bus and bus no's 2, 5, 8, 11, 13 are considered as a PV buses all other buses are considered as load buses. This system has 41 interconnected lines. A MATLAB program is coded for the test system and the results have been tabulated. Table 9 represents the generators coefficients, minimum and maximum limits of real power generation for generator buses.

Table 10 indicates that by using FA in OPF with SVC reduces the active power losses. By placing the SVC in bus no 22 active power losses are less in both GA and FA based OPF. In FA-OPF SVC value is tuned to 27MVAR, in GA-OPF it is tuned to 27.42MVAR.

Table 11 indicates the voltage magnitudes in FA-OPF without SVC and FA-OPF with SVC (by placing SVC at Bus No 22). There is an improvement in voltage profile with SVC in Firefly Algorithm based OPF. Table 12 indicates the fitness function value, SVC susceptance, voltage deviation, system loadability, transmission line losses and fuel cost of the generators for best worst and average cases. It is also indicates the computation time.

From the Figure 3 it is observed that by placing the SVC at bus 22 the active power losses are less as compared

Table 9. Generator characteristics of IEEE 30 bus system

\begin{tabular}{lllllr}
\hline $\begin{array}{l}\text { Generator } \\
\text { BUS NO }\end{array}$ & \multicolumn{1}{c}{ a } & b & c & $\boldsymbol{P}_{\boldsymbol{G}}^{\text {min }}$ & $\boldsymbol{P}_{\boldsymbol{G}}^{\text {max }}$ \\
\hline 1 & 0.00375 & 2 & 0 & 50 & 300 \\
2 & 0.0175 & 1.75 & 0 & 20 & 80 \\
5 & 0.0625 & 1 & 0 & 15 & 50 \\
8 & 0.00834 & 3.25 & 0 & 10 & 35 \\
11 & 0.025 & 3 & 0 & 10 & 30 \\
13 & 0.025 & 3 & 0 & 12 & 40 \\
\hline
\end{tabular}

Table 10. Incorporation OF SVC Model in FA- OPF and GA-OPF Algorithms in 5 different Locations

\begin{tabular}{lccccc}
\hline & $\begin{array}{c}\text { SVC } \\
\text { placed } \\
\text { Bus } \\
\text { No }\end{array}$ & $\begin{array}{c}\text { FA-OPF } \\
\text { SVC } \\
\text { Size in } \\
\text { MVAR }\end{array}$ & $\begin{array}{c}\text { GA-OPF } \\
\text { SVC Size } \\
\text { in MVAR }\end{array}$ & $\begin{array}{c}\text { FA-OPF } \\
\text { Active } \\
\text { Power } \\
\text { Losses } \\
\text { in MW }\end{array}$ & $\begin{array}{c}\text { GA-OPF } \\
\text { Active } \\
\text { Power } \\
\text { Losses } \\
\text { in MW }\end{array}$ \\
\hline 1 & 22 & 0.2700 & 0.2742 & 4.3751 & 8.5882 \\
2 & 24 & 0.2275 & 0.2307 & 4.6028 & 8.8330 \\
3 & 21 & 0.2611 & 0.2652 & 4.4331 & 8.6486 \\
4 & 10 & 0.1699 & 0.1753 & 4.7543 & 8.9835 \\
5 & 12 & 0.2500 & 0.2600 & 4.8909 & 9.1434 \\
\hline
\end{tabular}


Table 11. Comparison of bus voltages for 30 bus system using FA-OPF without and with SVC

\begin{tabular}{|c|c|c|c|}
\hline $\begin{array}{l}\text { BUS } \\
\text { No }\end{array}$ & NR method & $\begin{array}{c}\text { FA-OPF } \\
\text { without } \\
\text { SVC }\end{array}$ & $\begin{array}{l}\text { FA-OPF } \\
\text { with SVC } \\
\text { at } 22 \text { bus }\end{array}$ \\
\hline & Voltage & Voltage & Voltage \\
\hline & Magnitude & Magnitude & Magnitude \\
\hline 1 & 1.06 & 1.06 & 1.06 \\
\hline 2 & 1.045 & 1.045 & 1.045 \\
\hline 3 & 1.027266 & 1.028235 & 1.032764 \\
\hline 4 & 1.019596 & 1.020599 & 1.026199 \\
\hline 5 & 1.01 & 1.01 & 1.01 \\
\hline 6 & 1.011907 & 1.01265 & 1.017027 \\
\hline 7 & 1.002905 & 1.003225 & 1.005843 \\
\hline 8 & 1.01 & 1.01 & 1.01 \\
\hline 9 & 1.014133 & 1.014833 & 1.029354 \\
\hline 10 & 0.980569 & 0.982241 & 1.009472 \\
\hline 11 & 1.082 & 1.082 & 1.082 \\
\hline 12 & 1.021767 & 1.021194 & 1.033365 \\
\hline 13 & 1.071 & 1.071 & 1.071 \\
\hline 14 & 1.001627 & 1.001101 & 1.016342 \\
\hline 15 & 0.992281 & 0.992394 & 1.00917 \\
\hline 16 & 0.996244 & 0.997136 & 1.014808 \\
\hline 17 & 0.980112 & 0.98138 & 1.006107 \\
\hline 18 & 0.973943 & 0.974644 & 0.995341 \\
\hline 19 & 0.966394 & 0.967427 & 0.990418 \\
\hline 20 & 0.968152 & 0.969364 & 0.993416 \\
\hline 21 & 0.959493 & 0.961112 & 0.998779 \\
\hline 22 & 0.957625 & 0.959215 & 1 \\
\hline 23 & 0.971142 & 0.971629 & 0.994438 \\
\hline 24 & 0.95182 & 0.952766 & 0.983589 \\
\hline 25 & 0.958584 & 0.959512 & 0.979778 \\
\hline 26 & 0.939777 & 0.940724 & 0.961395 \\
\hline 27 & 0.972113 & 0.973005 & 0.986612 \\
\hline 28 & 1.005712 & 1.006278 & 1.011066 \\
\hline 29 & 0.951454 & 0.952367 & 0.966292 \\
\hline 30 & 0.939691 & 0.940616 & 0.954722 \\
\hline
\end{tabular}

Table 12. FA OPF SVC located at Bus no 22, for IEEE 30 bus system

\begin{tabular}{lrcc}
\hline & BEST CASE & $\begin{array}{c}\text { WORST } \\
\text { CASE }\end{array}$ & $\begin{array}{c}\text { AVERAGE } \\
\text { CASE }\end{array}$ \\
\hline $\mathrm{F}$ & 268.8000 & 278.1435 & 273.33138 \\
$\mathrm{~B}$ & 0.2583 & 0.2736 & 0.27 \\
$\mathrm{VD}$ & 0.6971 & 0.7014 & 0.6991 \\
$\mathrm{~S}$ & 3.2363 & 3.3996 & 3.32294 \\
$\mathrm{TL}$ & 4.3117 & 4.9481 & 4.3751 \\
$\mathrm{FC}$ & 921.4147 & 889.7361 & 905.09698 \\
Computation & 31.043397 & 32.104227 & 31.423823 \\
Time & & & \\
\hline
\end{tabular}

to other buses. The Active power losses are 4.3751MW when the SVC is placed in bus no 22. The active power generation, fuel cost of generators and power loss for IEEE 30 bus test system without and with SVC is shown in Table 13. It is observed that active power losses are reduced to $4.3751 \mathrm{MW}$ from $10.5923 \mathrm{MW}$ by placing SVC in FA based OPF. Table 14 represents the voltage deviation, SVC susceptance value and active power losses for IEEE 30 bus system without SVC and with SVC using GA-OPF and FA-OPF for different loading conditions.

Figure 4 represents the real power losses for different loading conditions using GA-OPF, FA-OPF without and with SVC. It indicates that increase in load increases the real power losses. For all loading conditions losses are less with FA based OPF incorporating the Static VAR Compensator.

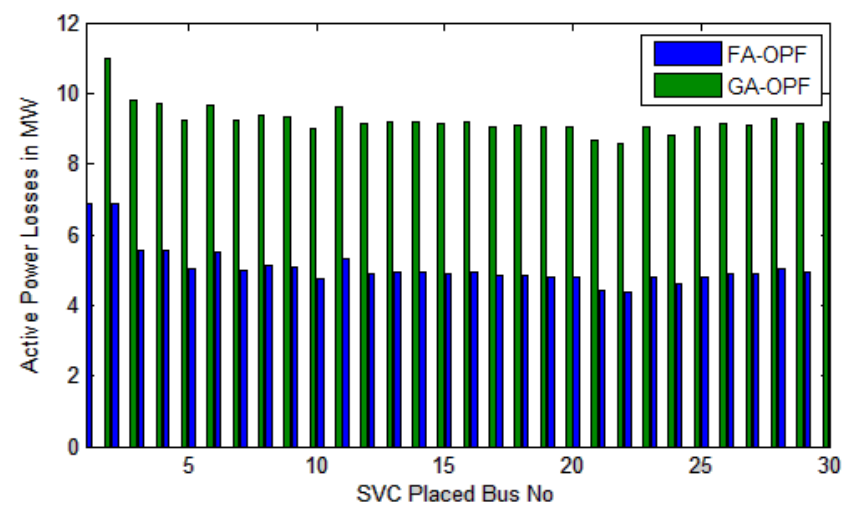

Figure 3 Comparison of active power losses in a 30 bus system

Table 13. Comparison of Real power loss for 30 bus test system without and with SVC (SVC placed at bus number 22)

\begin{tabular}{lllccc}
\hline S.No Method & $\begin{array}{c}\text { Real power } \\
\text { generation } \\
(\mathrm{MW})\end{array}$ & $\begin{array}{c}\text { Total real } \\
\text { power } \\
\text { loss } \\
(\mathrm{MW})\end{array}$ & Fuel cost & $\begin{array}{c}\text { Time for } \\
\text { computation }\end{array}$ \\
\hline 1 & $\begin{array}{l}\text { NR method } \\
\text { NR with SVC }\end{array}$ & 293.9923 & 10.5923 & - & 0.089441 \\
2 & $\begin{array}{l}\text { (B }=0.2726) \\
\text { (B) }\end{array}$ & & & & \\
3 & $\begin{array}{l}\text { GA-OPF } \\
\text { without SVC }\end{array}$ & 293.3875 & 9.9875 & - & \\
4 & $\begin{array}{l}\text { GA-OPF } \\
\text { with SVC }\end{array}$ & 291.9882 & 8.5882 & 953.41066 & \\
5 & $\begin{array}{l}\text { FA-OPF } \\
\text { without SVC }\end{array}$ & 288.8165 & 5.4165 & 902.90644 & 31.423823 \\
6 & $\begin{array}{l}\text { FA-OPF with } \\
\text { SVC }\end{array}$ & 287.7751 & 4.3751 & 905.09698 & \\
\hline
\end{tabular}


Table 14. Real Power loss, Voltage deviation and rating of SVC for different load scenario for IEEE 30 bus system using GA and FA (SVC placed at bus no 22)

\begin{tabular}{|c|c|c|c|c|c|}
\hline $\begin{array}{l}\text { Loading } \\
\text { condition }\end{array}$ & & GA-OPF & $\begin{array}{l}\text { GA-OPF } \\
\text { with SVC }\end{array}$ & FA-OPF & $\begin{array}{l}\text { FA-OPF } \\
\text { with SVC }\end{array}$ \\
\hline \multirow{3}{*}{$\begin{array}{l}\text { Normal } \\
\text { loading }\end{array}$} & SVC Rating & - & 0.2742 & - & 0.2700 \\
\hline & $\begin{array}{l}\text { Voltage } \\
\text { Deviation }\end{array}$ & 0.9214 & 0.6598 & 0.9106 & 0.6347 \\
\hline & $\begin{array}{l}\text { Real Power } \\
\text { losses }\end{array}$ & 9.9796 & 8.5882 & 5.4165 & 4.3751 \\
\hline \multirow{3}{*}{$\begin{array}{l}110 \% \\
\text { loading }\end{array}$} & SVC Rating & - & 0.3436 & - & 0.3358 \\
\hline & $\begin{array}{l}\text { Voltage } \\
\text { Deviation }\end{array}$ & 1.0620 & & 1.0543 & \\
\hline & $\begin{array}{l}\text { Real Power } \\
\text { losses }\end{array}$ & 11.6941 & 11.284 & 7.1524 & 6.48 \\
\hline \multirow{3}{*}{$\begin{array}{l}120 \% \\
\text { loading }\end{array}$} & SVC Rating & - & 0.4047 & - & 0.3987 \\
\hline & $\begin{array}{l}\text { Voltage } \\
\text { Deviation }\end{array}$ & 1.2118 & 0.7743 & 1.2074 & 0.7266 \\
\hline & $\begin{array}{l}\text { Real Power } \\
\text { losses }\end{array}$ & 13.840 & 12.82 & 9.4997 & 8.79 \\
\hline \multirow{3}{*}{$\begin{array}{l}150 \% \\
\text { loading }\end{array}$} & $\begin{array}{l}\text { SVC } \\
\text { Rating }\end{array}$ & - & 0.65 & - & 0.6268 \\
\hline & $\begin{array}{l}\text { Voltage } \\
\text { Deviation }\end{array}$ & 6.0343 & 0.8290 & 5.0043 & 0.8093 \\
\hline & $\begin{array}{l}\text { Real Power } \\
\text { losses }\end{array}$ & 50.969 & 35.16 & 41.687 & 32.67 \\
\hline
\end{tabular}

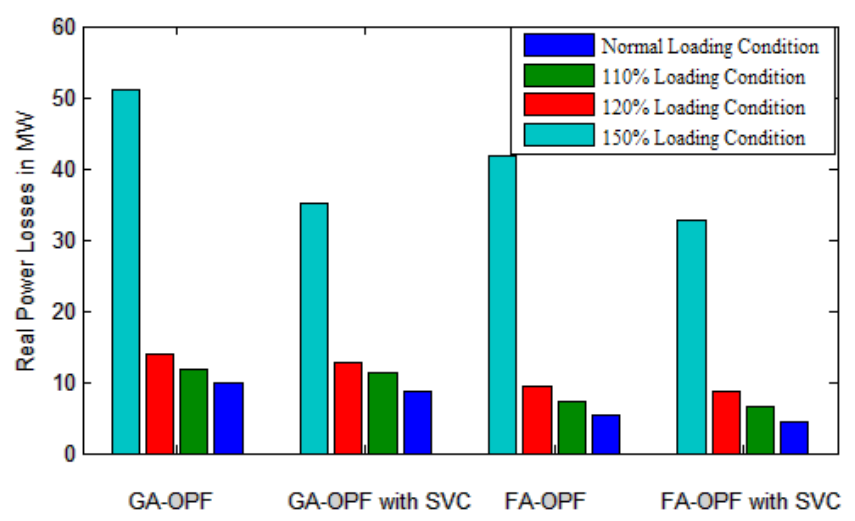

Figure 4 Real power Losses before and after placement of SVC for different loading condition.

\section{Conclusion}

In this paper, sensitivity analysis based Voltage Collapse Proximity Indicator has been implemented for optimal location of SVC and a new swarm based Firefly Algorithm has been presented to solve the optimal allocation of SVC. The effectiveness of FA was demonstrated and tested. The results show that incorporating the SVC in the IEEE 14 bus and IEEE 30 bus system can reduce the total active power losses and improve the voltage profile of the system.
An application of FA optimization for finding the best allocation of an SVC within a power system network, with the objective of reducing voltage deviations, total power losses, total generation cost and branch loading is also presented. Comparison with GA has also been done to see the performance of FA in solving the optimal allocation problem. The proposed approach presents the effective results. The sensitivity analysis based Firefly Algorithm optimization method has been used to identify optimal location and size of the SVC.

\section{References}

1. Kundur P. Power System Stability and Control. New York: McGraw-Hill, Inc.; 1993.

2. Stagg GW, El-Abid AH. Computer Methods In Power System Analysis. McGraw-Hill Book Co; 1968.

3. Hingorani NG, Gyugyi L. Understanding FACTS: Concepts and Technology of Flexible AC Transmission System. IEEE Press; 2000.

4. Song YH, Johns AT. Flexible AC Transmission Systems (FACTS). IEE Press, U.K., 1999. Acha E., Fuerte-Esquivel C, Ambriz-Perez H and Angeles C., "FACTS: Modeling and Simulation in Power Networks". John Wiley \& Sons, 2004.

5. Acha E, Fuerte-Esquivel CR, Ambriz-Perez H, AngelesCamacho C. FACTS Modelling and Simulation in Power Networks.

6. Hsmmns TJ, Lim SK. Flexible AC Transmission System (FACTS). Ekctnic Machines \& Power System VD1.25, w. 73-85.1997.

7. Ambriz-Perez H, Acha E, Fuerte-Esquivel CR. Advanced SVC models for Newton-Raphson Load Flow and Newton Optimal Power Flow studies. IEEE Trans.on Power Systems. 2000; 15(1) 129-36.

8. Canizares CA, Faur ZT. Analysis of SVC and TCSC controllers in voltage collapse. IEEE Trans. on Power Systems. 1999; 14(1):158-65.

9. Mansour Y, Xu W, Alvarado F, Rinzin C. SVC placement using critical modes of voltage instability. IEEE Trans on Power Systems. 1994 May; 9(2):757-63.

10. Carpentier. Optimal power flows. Electrical Power and Energy Systems. 1979 Apr; 1:959-72. Carpentier I.L., "Optimal Power Flows: Uses, Methods and Developments". Proceedings of IFAC Conference. 1985.

11. Sun DI, Ashley B, Brewer B, Hughes A, Tinney WF. Optimal power flow by newton approach. IEEE Transactions on Power Apparatus and Systems. 1984; 103(10):2864-80.

12. Tinney WF, Hart CE. Power flow-solution by Newton's method. IEEE Transactions (PAS). 1967; 86:1449.

13. Yang XS. Nature-inspired Metaheuristic Algorithms. Luniver Press; 2008. 
14. Cherkaoui GR, Germond AJ. Optimal location of multi-type FACTS devices in a power system by means of genetic algorithms. IEEE Trans Power Syst. 2001 Aug; 16:537-44.

15. Mansour Y, Xu W, Alvarado F, Rinzin C. SVC placement using critical modes of voltage instability. IEEE Trans on Power Systems. 1994 May; 9(2):757-63.

16. Chug TS, Qifeng D, Bomina Z. Optimal active OPF with FACTS devices by innovative load-equivalent approach. IEEE Power Eng Rev. 2000 May; 20(5):63-6.

17. Chung TS, Li YZ. A hybrid ca approach for OPF with consideration of FACTS devices. IEEE Power Eng Rev. 2001 Feb; 21(2):47-50.

18. Yu X, Singh C, Jakovljevic S, Ristanovic D, Huang G. Total transfer capability considering FACTS and security constraints. Transmission and Distribution Conference and Exposition. IEEE PES. 2003 Sep 7-12; 1:73-8 .

19. IEEE Power Engineering Society, "FACTS Applications", Publication 96 TP 116-0, IEEE Press, New York, 1996

20 Xiao Y, Song YH, Sun YZ. Power flow control approach to power systems with embedded FACTS devices. IEEE Trans Power Syst. 2002 Nov; 17(4):943-50.

21. Perez MA, Messina AR, Fuerte-Esquivel CR. Application of FACTS devices to improve steady state voltage stability. Power Engineering Society Summer Meeting. IEEE. 2000 Jul 16-20; 2:1115-20.

22. Mansour $\mathrm{Y}, \mathrm{Xu}$ W, Alvarado F, Rinzin C. SVC placement using critical modes of voltage instability. IEEE Trans on Power Systems. 1994 May; 9(2):757-63.

23. Pilotto LAS, Ping WW, Carvalho AR, Wey A, Long WF, Alvarado FL, Edris A. Determination of needed FACTS controllers that increase asset utilization of power systems. IEEE Trans on Power Delivery. 1997 Jan; 12(1):364-71.
24. Xiao Y, Song YH, Sun YZ. Power flow control approach to power systems with embedded FCATS devices. IEEE Trans Power Syst. 2002 Nov; 17(4):943-50.

25. Yang XS. Firefly algorithm, Levy flights and global optimization. Research and Development in Intelligent Systems XXVI. UK: Springer, London; 2010.

26. Lukasik S, Zak S. Firefly algorithm for continuous constrained optimization tasks. Proceedings of the International Conference on Computer and Computational Intelligence (ICCCI '09). Nguyen NT, Kowalczyk R, Chen S-M, editors. Poland: Springer, Wroclaw; 2009 Oct.

27. Yan X-S. Firefly algorithm for constrained optimization. Available from: www.mathworks.com/matlabcentral/fileexchange/ 29693-firefly-algorithm

28. Yang X-S. Firefly algorithms for multimodal optimization. Stochastic Algorithms: Foundation and Applications SAGA. 2009; 5792:169-78.

29. Yorino N, El-Araby EE, Sasaki H, Harada S. A new formulation for FACTS allocation for security enhancement against voltage collapse. IEEE Trans on Power Systems. 2003 Feb; 18(1): 3-10.

30. Praing Ch, Tran-Quoc T, Feuillet R, Sabonnadiere JC, Nicolas J, Nguyen-Bio K, Nguyen-Van L. Impact of FACTS devices on voltage and transient stability of a power system including long transmission lines. Ieee Power Engineering Society Meeting. 2000; 3:1906-11.

31. Janson Y, Kit WP. Evolutionary programming based optimal power flow algorithm. IEEE Trans Power System. 1999; 14(4):1245-50.

32. Perez MA, Messina AR, Fuerte-Esquivel CR. Application of FACTS devices to improve steady state voltage stability. Power Engineering Society Summer Meeting. IEEE. 2000 Jul 16-20; 2:1115-20. 